\title{
Hävitys, teknologia ja yhteisölliset symbolit Armémuseumissa Tukholmassa
}

\author{
Aaro Sahari'
}

Monelle Tukholman kävijälle tuttu Ruotsin valtion sotamuseo Armémuseum uudistaa näyttelyitään ja otettaan sodan ja turvallisuuden historiasta. Museo on perustettu Svean tykistörykmentiltä vapautuneisiin tiloihin Tukholman Österlmalmille vuonna 1879. Sen päänäyttelyt uudistettiin viimeksi 1990-luvun lopussa juuri ennen digitaalisen esitysteknologian saapumista museoihin. Museon oma historia kuvastaa osuvasti tätä menneisyyden painolastia. Monien muiden sotamuseoiden tapaan Armémuseumin kokoelmat ovat aihepiiriltään varsin raskaita, minkä takia oivaltavat keinot käsitellä sodan historiaa ovat tarpeen.

Sodankäynnin esineellistä kulttuuriperintöä on tyypillisesti säilynyt valtiollisissa kokoelmissa, joten sotamuseoiden historia on jo tästä syystä kansallista historiaa. Armémuseumin kokoelmissa pelkästään esineitä on keskiajalta nykypäivään yli 100000 pienistä arkeologisista fragmenteista kokonaisiin kylmän sodan aikaisiin asejärjestelmiin. Kokoelmien painopiste on ymmärrettävästi Ruotsin hetkittäin hyvinkin sotaisassa historiassa, minkä takia eri osapuolten tasapainoinen käsittely edellyttää tarkkaa näkökulmien valintaa. Sodan jalkoihin jääneiden siviilien kohtalot ja sodan muistamisen erilaiset tavat on nostettu uuden sotahistorian tutkimuksen myötä tarkastelun keskiöön. Samalla näyttelyt ovat alkaneet avautua aiempaa monipuolisemmille tarinoille. Erinomaisen esimerkin tästä tarjoaa Armémuseumin uusin näyttely.

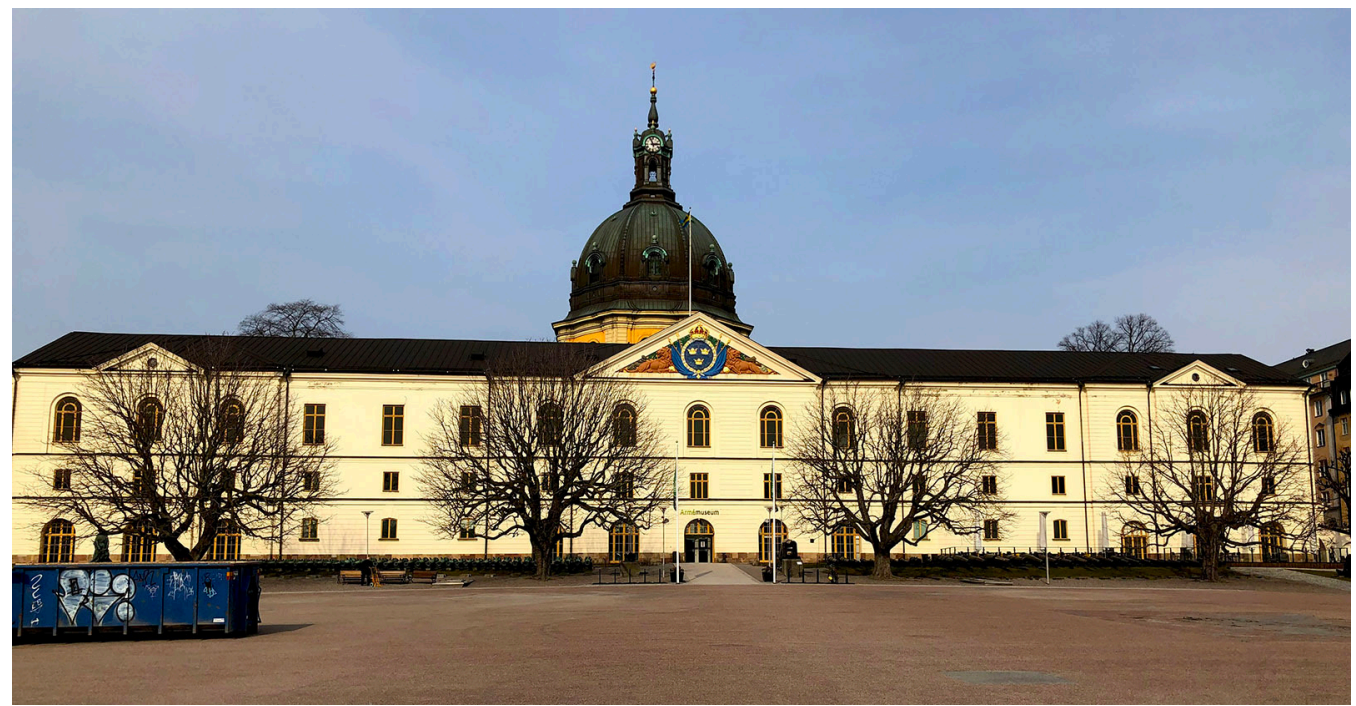

Kuva 1. Yli-intendentti Carl Johan Cronstedtin ja eversti Carl Ehrensvärdin 1760-luvulla suunnittelema Armémuseum kylpee kevätauringossa Tukholman Östermalmilla. Kuva: Aaro Sahari, CC BY 4.O.

\footnotetext{
${ }^{1}$ Kirjoittaja on Suomen kansallismuseon tutkija Jane ja Aatos Erkon Säätiön rahoittamassa hankkeessa Historia eläväksi, jonka tavoitteena on luoda virtuaalinen elämys Ruotsinsalmen toisesta meritaistelusta kesällä 1790. Ruotsin ja Venäjän välistä sotaa ja sen seurauksia käsitellään vuonna 2020 avautuvassa näyttelyssä Kohtalona Ruotsinsalmi.
} 
Kuva 2. Valtavat 1700-luvun alun armeijaliput on aseteltu näyttävästi Narvan taistelua käsittelevään näyttelyyn. Kuva: Marcus Lepola, Suomen merimuseo.

Lokakuussa 2018 avautunut näyttely Segerns pris - Narva 1700 (voiton hinta) edustaa museon uutta otetta. Suuren Pohjan sodan alussa marraskuussa 1700 Ruotsin ja Venäjän välillä käyty Narvan tais-

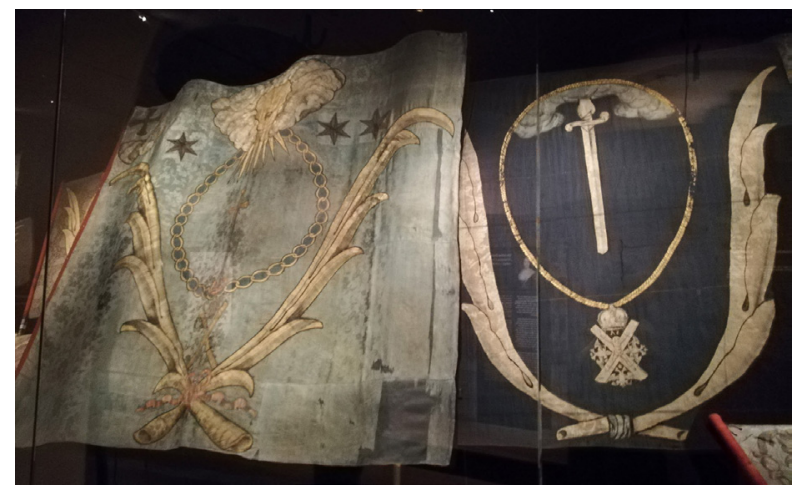
telu päättyi ensimmäisen voittoon sekä suuriin juhliin Tukholman kaduilla. Vuosikymmeniä kestänyt sota johti kuitenkin Ruotsin suurvaltakauden päättymiseen, eikä sodan tai kuningas Kaarle XII:ta muisto ole särötön. Narvan taistelussa lyötyjen venäläisten osastojen taisteluliput kuuluvat Armémuseumin kokoelmiin, ja niiden avulla museo nyt kertoo edustavan tarinan sotapropagandasta, kansallisista ja yhteisöllisistä symboleista sekä sodan "veriuhrin" banaaliudesta.

Segerns pris -näyttely on rakennettu Narvan ensimmäisen taistelun trofeiden varaan, mutta näyttely ei niinkään käsittele itse sotaa vaan sitä koskevaa aikalaiskeskustelua. Tarina alkaa ruotsalaisesta kirkosta, jossa pappi lukee taistelua koskevan julistuksen, aikansa valtiollisen uutisen. Tämän jälkeen kävijä pääsee tutustumaan Tukholmassa pidettyyn paraatiin, jossa lippuja esiteltiin taistelun jälkeen kansallisen hurmoksen hengessä. Seuraavaksi

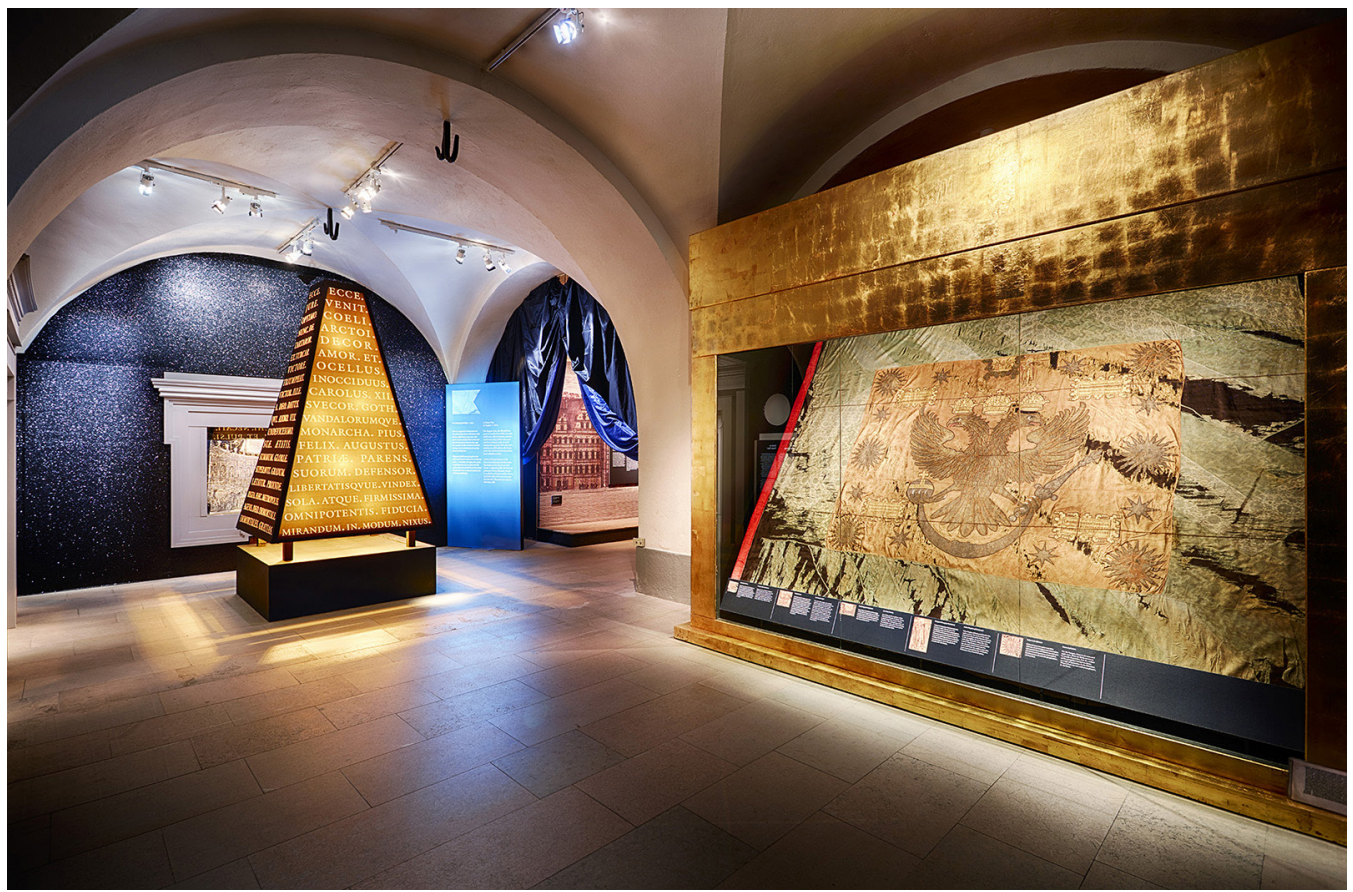

Kuva 3. Narvan taistelun venäläisen armeijan liput ovat näyttävästi esillä. Kerronnassa ne rinnastetaan nykyaikaisiin lippuihin ja yhteisöllisten symboleiden käyttöön. Kuva: Armémuseum, https:// news.cision.com/se/armemuseum . 


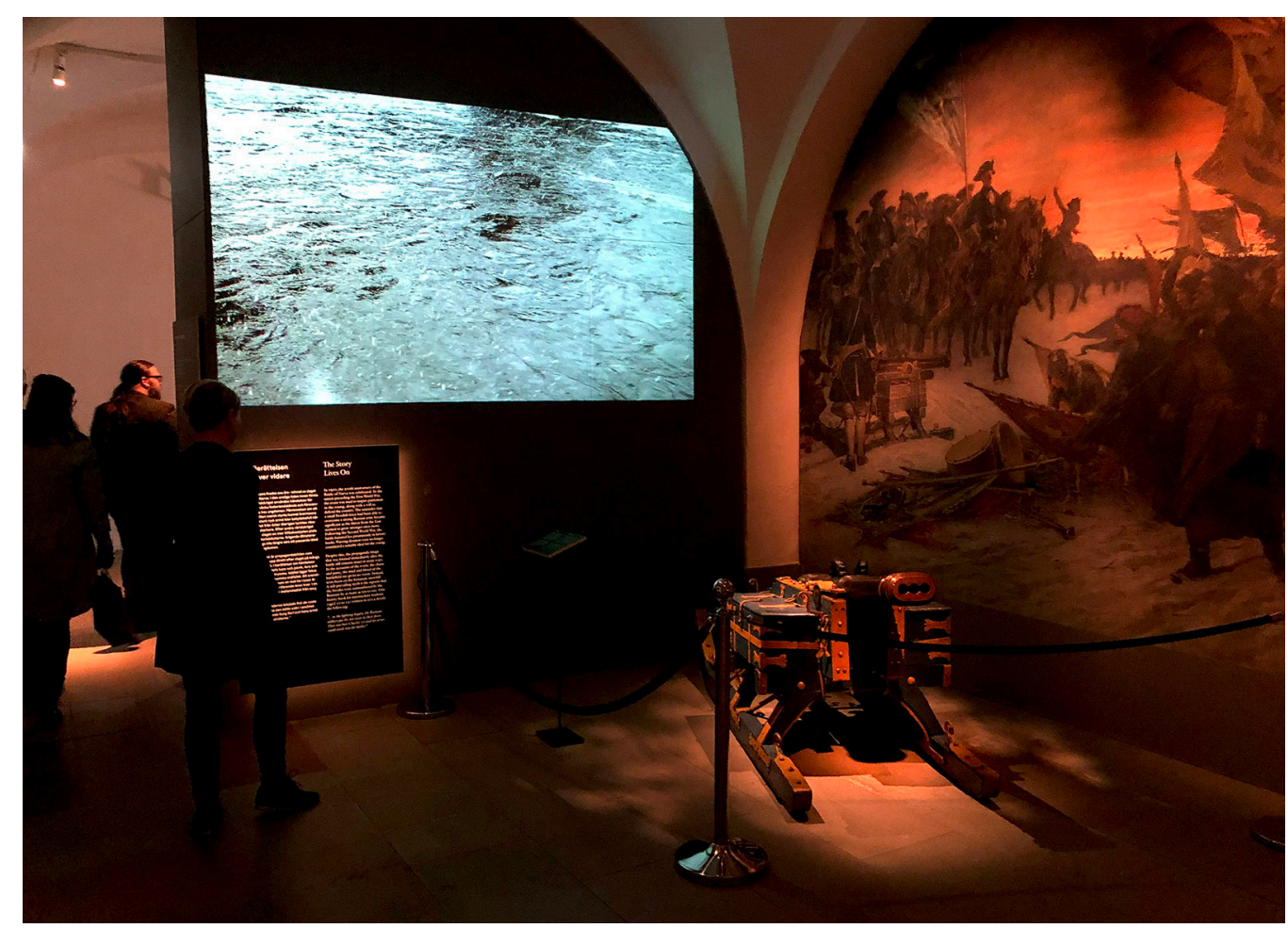

Kuva 4. Kokeellinen tykki on säilynyt tykistökokoelmassa, mutta sitä on käsitelty myös taiteessa. Seinälle toistetun maalauksen iltarusko vahvistuu valaistuksen avulla ja hienovarainen videoinstallaatio täydentää taistelun jälkeistä tunnemaisemaa. Kuva: Aaro Sahari, CC BY 4.O.

tarina saa synkempiä sävyjä. Rinnastamalla menneisyyden sotaisat symbolit oman aikamme mielenosoituksista tuttuihin lippuihin näyttely kutsuu museokävijän pohtimaan omia yhteisöllisiä arvojaan ja moderneja heimotunnuksiaan, olivat ne sitten poliittisia, populaareja tai kaupallisia. Lopuksi näyttely kehottaa harkitsemaan voiton hintaa, tuhansia menetettyjä ihmishenkiä.

Näyttely onnistuu erinomaisesti yhdistämään perinteistä museokerrontaa ja esittämistekniikoita erinäisiin digitaalisiin ja monimediaisiin kerrontatapoihin. Erilaiset video- ja ääniinstallaatiot eivät jää yksin, vaan ne on suunniteltu osaksi kokonaisvaltaista tarinaa. Esineet, kuvat ja historiaa lisäävä teknologia tukevat ja täydentävät toisiaan.

Armémuseum on suuri museo, eivätkä sen näyttelyt ole yhdestä puusta veistettyjä. Ruotsin sotahistoriaa keskiajalta nykypäivään käsittelevä päänäyttely on peräisin 1990-luvun lopusta, joskin sitä on sittemmin jatkuvasti uudistettu. Museon päänäyttely Krig och fred (sota ja rauha) jakautuu 1900-luvun taitteen ympärille kahteen osioon museon kahdessa kerroksessa. Jako korostaa ruotsalaisen yhteiskunnan suurta muutosta sodan suhteen. Ruotsin viimeinen sota Norjan valloittamiseksi Tanskalta 1800-luvulla on osa vanhempaa sotaisaa historiaa, johon kuuluvat myös maan suurvaltakauden toistuvat sodat sekä Suomen menetys Venäjälle 1809. Tätä vastoin nyky-Ruotsin suhde sotaan on etäisempi ja analyyttisempi. Näyttelyn 1900-luvun historiaa käsittelevä osa heijastelee tätä muutosta. 


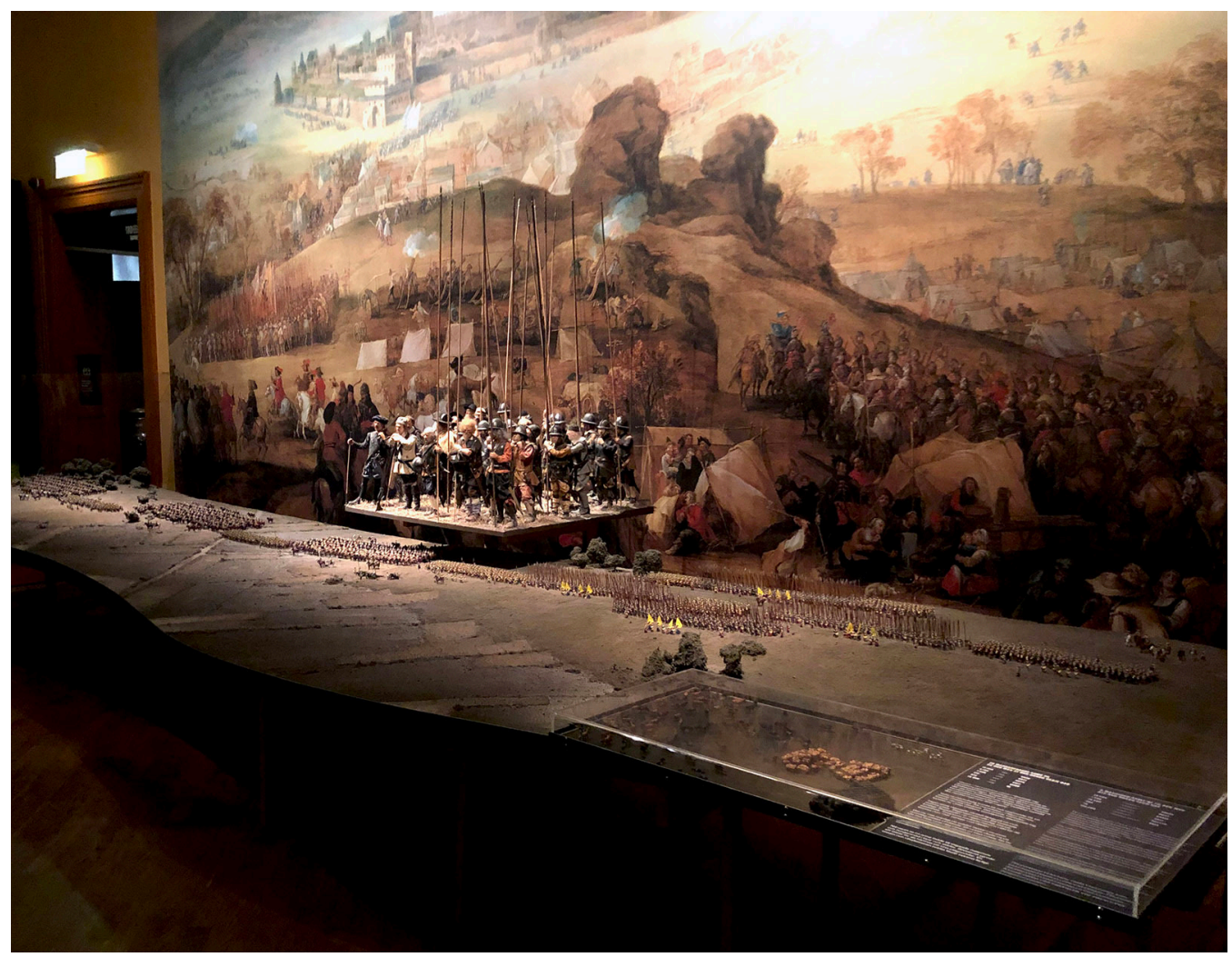

Kuva 5. Armémuseumin näyttelyiden suuret dioraamat ja pienoismallit täydentävät uusia digitaalisia taisteluesityksiä. Niiden avulla historiallisten armeijoiden mittakaava avautuu yhä oivallisesti, vaikka liike puuttuukin. Kuva: Aaro Sahari, CC BY 4.0.

Yhteiskunnan suhde sotaan on näyttelyssä paitsi sosiaalinen myös tekninen. Näyttely avautuu väkivallan ajattomuuden pohdinnalla ihmisen esivanhemmista mannertenvälisiin ydinohjuksiin. Korkealentoisen aloituksen jälkeen näyttely asettuu perinteiseen kronologiseen kerrontaan, jossa Ruotsin valtakunnan historian eri sotia peilataan aikakauden sosiaalisiin teemoihin yhteiskuntaluokkien välisistä suhteista infrastruktuurin kehitykseen ja teollisuuden ja talouden kysymyksiin. Näytteillä olevat esineet kertovat museon kokoelmien historiasta; aseet ja haarniskat saavat etusijan vanhempien aikojen esittelyssä. Puutteita on täydennetty näyttävin, suorastaan suureellisin kuvaelmin. Välillä uusi digitaalinen teknologia pilkistää tämän selvästi aikaansa jääneen tyylin lomasta. Museon henkilökunta tunnistaakin vanhentuvan näyttelyn ongelmat. Yksittäisiä osioita on uudistettu ja uudistuksia on tarkoitus jatkaa vastedeskin. Suuri tarina Kustaa Vaasan vallankumouksesta Suomen sotaan muodostaa silti tarinan punaisen langan.

Lähihistorian osio on suurelta osin uudistamatta toisin kuin vanhempia aikoja käsittelevät näyttelyt. 1900-luvun kertomus jakautuu kahtia suuriin globaaleihin muutoksiin ja Ruotsin tapaan reagoida tähän muuttuvaan maailmaan. Vahvimmin lähihistorian väkivaltaisuus tulee iholle näyttelyosiossa, jossa avataan lähettiläs Raoul Wallenbergin humanitaarisia tekoja Unkarissa toisen maailmansodan aikana. Silti 1900-lukua käsittelevä näyttely nostaa tarkoi- 


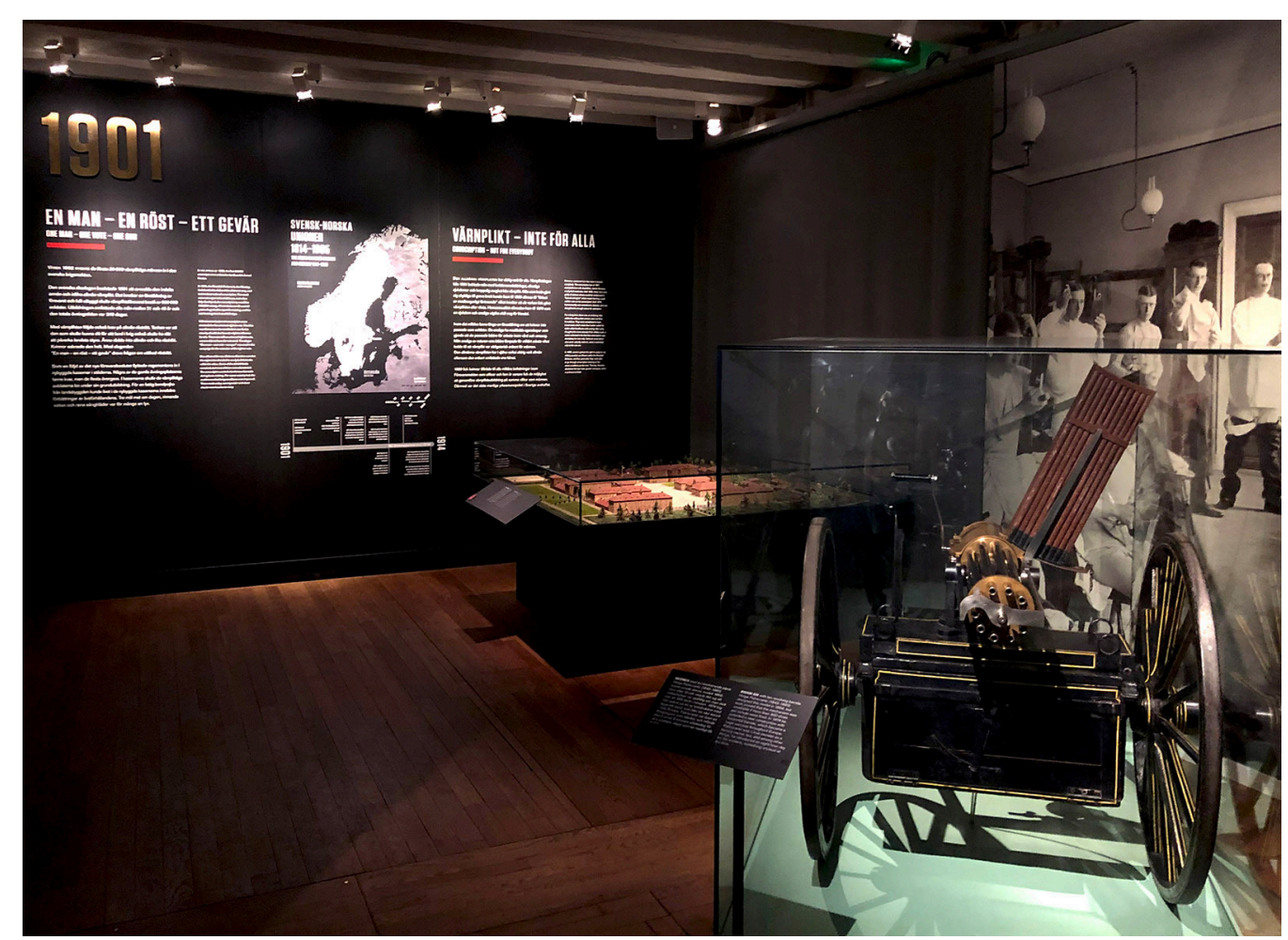

Kuva 6. 1900-lukua käsittelevässä näyttelyosiossa teknologinen kehitys nousee pakostakin tarinan keskiöön. Taistelukuvausten sijaan se esitetään kasarmin ja globaalin turvallisuuden kontekstissa. Kuva: Aaro Sahari, CC BY 4.0.

tuksetta esille sotamuseoille ongelmallisen aiheen, rauhan. Mitä käsitellään, kun ei käsitellä sotaa? Näyttelytekstien yleiset tarinat peilaavat historiantutkimusta, mutta esineiden kautta avautuu näkymä tehostuvan ja teknistyvän tuhon maailmasta.

Erityisen ongelmallinen on päänäyttelyn viimeinen osio, Moderna vapen (modernit aseet). Ruotsi ei ehkä ole 1900-luvulla käynyt sotia, mutta ruotsalaiset aseet ovat. Sotatalous ja -teollisuus ovat syystä osa näyttelyn tarinaa, mutta esineiden asettelu ei heijastele tekstien kriittistä sävyä. Hetkittäin tavassa esittää aseita ja sodankäynnin koneita tulee pikemminkin mieleen messuhalli. Aseet on nimetty ja niiden teknologista kehitystä on avattu, mutta niiden suhde elävään elämään jää etäiseksi ja kylmäksi. Moderni sotateknologia on jo lähtökohdiltaan elämästä etäännyttävää. Johtokeskuksesta ohjattu lennokki on poistanut ihmistiedustelijat välittömästä vaarasta. Sen esittäminen mykkänä esineenä etäännyttää koneen kuitenkin sen käyttötarkoituksesta. Ehkä ruotsalaisten rauhanturvaajien videoita Afganistanista tai joltain muulta nykypäivän konfliktialueelta ei voi esittää museossa, mutta ero vanhemman historian väkivaltaisuuteen on huomattava. Miksi siis inhimillinen kärsimys muuttuu sitä valjummaksi, mitä kauemmas ajassa mennään? Ruotsalaisen ratsuväen rynnäkkö vavisuttaa kävijää fyysisyydellään, mutta onko se lopulta kauheampi kuin modernit sodan koneet? 


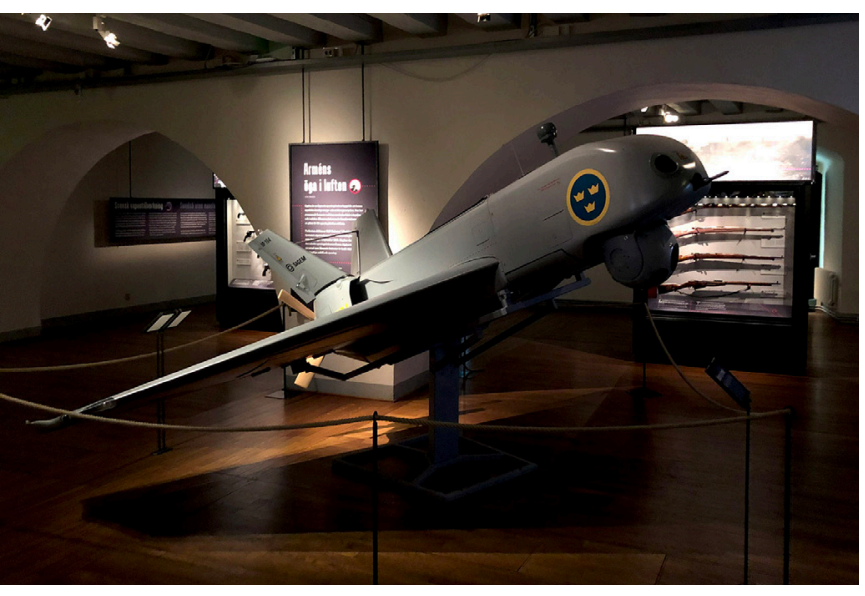

Kuvat 7 ja 8. Nykyaikaista teknologiaa esitetään kliinisesti ja estetisoiden... Kuva: Aaro Sahari, CC BY 4.0.

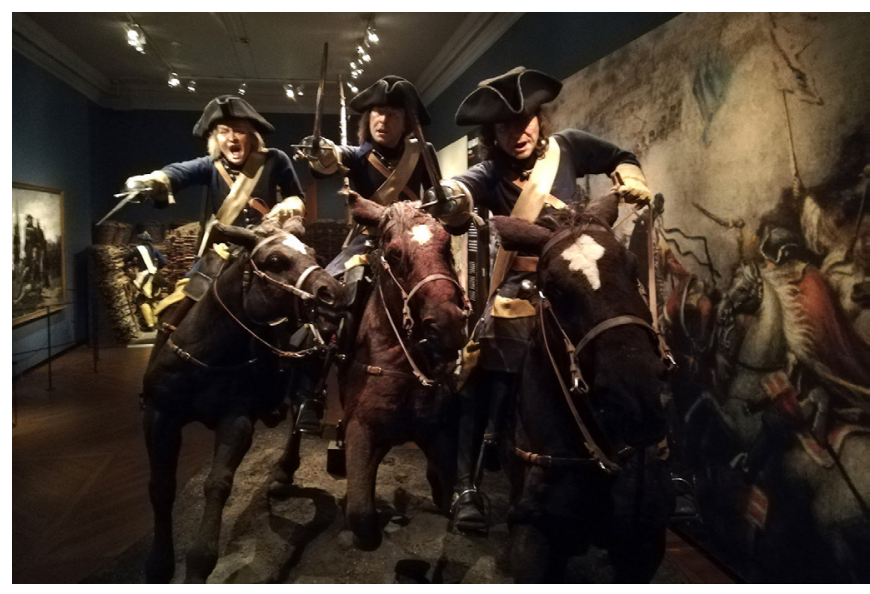

...mutta vanhaa sodankäyntiä tapahtumia ja käyttöä korostaen.

Kuva: Marcus Lepola, Suomen merimuseo.

Armémuseum jättää kävijälle monia kysymyksiä sodasta, rauhasta, kansakunnasta ja ihmiselämästä. Vastauksia ei kannata odottaa kaikkiin vakavaa aihetta koskeviin kysymyksiin. Uusimmissa näyttelyissään museo onnistuu erinomaisesti purkamaan vaikeita ilmiöitä sekä älyllisesti että tunteellisesti. Samalla uusimmat näyttelyt asettavat vanhemmat osiot kiittämättömään asemaan. Sodan esittämisen tavat ovat muutoksessa, minkä takia toivonkin, että sotamuseot saisivat tarvitsemansa resurssit näyttelyidensä uudistamiseen. Pelkkä mykkä rauta hämärässä makasiinissa ei enää riitä avaamaan sodan historiaa.

\section{Lisätietoa:}

Armémuseum, Riddargatan 13, Östermalm, Stockholm https://www.armemuseum.se/

Raoul Wallenbergin elämästä lisää löytyy tämän nimeä kantavan instituutin sivuilta osoitteesta https://rwi.lu.se/about/about-raoul-wallenberg/ 